\title{
Total abdominal hysterectomy in a Tertiary Hospital in Kumasi: Indication, Histopathological Findings and Clinicopathological Correlation
}

\author{
N. A. Titiloye ${ }^{1}$, B. M. Duduyemi1 1 , E. A. Asiamah², I. Okai ${ }^{3}$, P. P. S. Ossei1 ${ }^{1}$ T. O. \\ Konney ${ }^{4}$, and P. K. Fefemwole ${ }^{1}$ \\ ${ }^{1}$ Department of Pathology, ${ }^{3}$ Department of Anatomy, ${ }^{4}$ Department of Obstetrics and Gynaecology, Kwame Nkrumah University of Science \\ and Technology, Kumasi. ${ }^{2}$ Department of Medical Laboratory Science, University of Health and Allied Sciences, Ho, Ghana.
}

\begin{abstract}
Hysterectomy is the commonest gynaecological surgery worldwide. Hysterectomy is commonly performed in our centre with request for post-surgical histological confirmation of pathologies. The aim of this study was to review all the hysterectomy specimens sent to our department between 2008 and 2016 and analyse the histological diagnosis in them and clinically correlate with the indications for the surgery. We reviewed retrospectively request forms, histological reports and slides generated for all cases of hysterectomies sent to our department for histological assessment between 2008 and 2016 totalling 1086. All the data obtained were analysed using SPSS 21. A total number of 1086 cases of hysterectomies with or without salpingooophorectomy were received in our department. The age range was 15 to 85 years with age group 40 to 49 years constituting $57.7 \%$ of cases. The commonest indication for surgery was uterine mass which constituted 722 cases $(66.42 \%)$ and an obvious uterine mass was found at grossing in 737 cases $(66.48 \%)$ while histology revealed uterine leiomyoma in 861 cases $(79.28 \%$ ) constituting the largest proportion of histological diagnosis. Other indications for surgery include dysfunctional uterine bleeding, suspected ovarian and cervical malignancy and peri-partum haemorrhage. Histological diagnoses confirmed wide range of lesions within the endometrium, cervix, fallopian tubes and ovaries. There was correlation between clinical indication and histological diagnosis up to $90.2 \%$ of all cases. Our data confirmed hysterectomy specimens with or without salpingo-oophorectomy as a common histological specimen in our laboratory, with peak age of patients in the fifth decade. Leiomyoma was the commonest histological finding and other wide ranges of pathologies were seen with strong positive $(\mathrm{r}=0.98)$ correlation between pre-operative indication and the final diagnosis.

Journal of Medical and Biomedical Sciences (2018) 7(1), 22 - 28
\end{abstract}

Keywords: Hysterectomy, gynaecological, histological, pathologies, salpingo-oophorectomy.

\section{INTRODUCTION}

The commonest gynaecological surgery worldwide is hysterectomy, and it is also the second most common surgical procedure in USA (Wu et al., 2007; Graves 1990). The hallmark for diagnosis of lesions from hysterectomy specimen is histology therefore hysterectomy specimen forms a significant proportion of all surgical specimen submitted for histopathological analysis in various tertiary teaching

Correspondence: Dr Nicholas Akinwale Titiloye, Department of Pathology, KNUST, Kumasi. Ghana.

E-mail: Waleht2000@yahoo.com, or nicholastitiloye.sms@,knust.edu.gh hospitals worldwide including West Africa (Adelusola and Ogunniyi 2001; Samaila et al., 2009).

Previous study conducted at a tertiary teaching hospital in Ghana put the prevalence rate of hysterectomy at the Department of Obstetrics and Gynaecology in the Institution as $7.8 \%$ with uterine fibroid as the leading indication (Takyi 2013). Severe uterine bleeding from uterine rupture was the cause of peripartum hysterectomy in a study from same institution in Ghana (Kwame-Aryee et al., 2007).

Our hospital is a tertiary medical institution serving the Northern part of Ghana and there has not been 


\section{Abdominal hysterectomy in a tertiary hospital}

Titiloye et al.,

a previous study on hysterectomy specimens from our centre.

This study reviewed all cases of hysterectomy received at the Pathology Department of our hospital between 2008 and 2016 for histological analysis, with the aim of determining the indication for surgery, the pattern of lesions in the specimen and clinical correlation of these lesions with the indication.

\section{MATERIALS AND METHODS}

\section{Study design}

The design of the study was a retrospective study. We abstracted all cases of Hysterectomy with or without salpingo-oophorectomy received at the Department of Pathology of our hospital over a period of 9 years (2008-2016).

\section{Data collection}

The histology case identification numbers were used to retrieve the histology request forms, histology reports and slides from the department archive. Clinical demographic details were abstracted from the request forms and histopathological diagnoses from the reports. A review of the histopathological diagnoses was done using the retrieved slides. Where the slides were not available, sections were cut from archival blocks.

The Department received hysterectomy specimens from the in-patients within the hospital and other health facilities within the Northern part of Ghana during the study period. Specimens were transferred to the Department in 10\% neutral buffered formalin (NBF) and Haematoxylin and Eosin (H \& E) stained sections from the sampled specimens were produced for histological diagnosis by pathologists.

Cases whose request forms, histological reports and slides could not be retrieved were excluded from the study.

\section{Statistical analysis}

Data obtained were analysed using SPSS 21. Data was presented as chart, mean (standard deviation), number and percentage. Pearson correlation coefficient were used for association between gross mor- phology and histology with clinical indication. Pvalue $<0.05$ was considered statistically significant.

\section{RESULTS}

A total number of 1086 Hysterectomy specimens were studied. This is $2.68 \%$ of all histological cases within the study period. The cases were performed on patients from age range of $15-85$ years with a mean age of 45.96 (SD 9.24).

Most of our cases (57.7) were in the age range $40-$ 49 years; while age range of 30 -39 years and 50 -59 years recorded $16.3 \%$ and $19.43 \%$ respectively. The frequency at ages lower than 30 and ages above 60 were low (Figure 1).

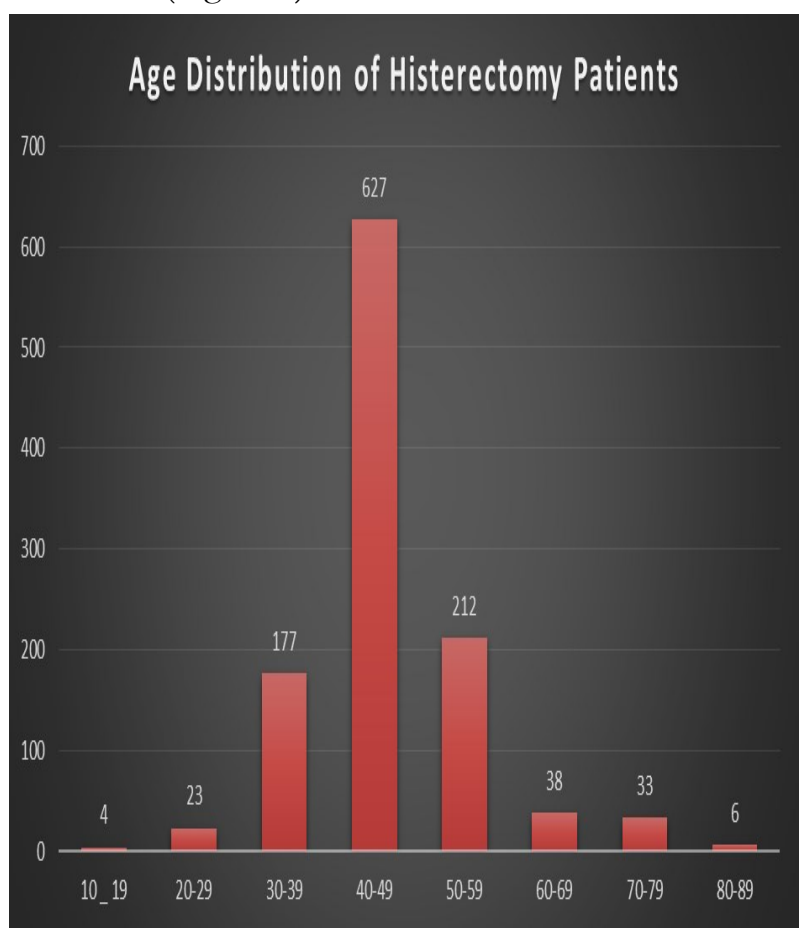

Figure 1: Age distribution of Hysterectomies

Total abdominal hysterectomy with bilateral salpingo-oophorectomy have the highest frequency of occurrence accounting for 434 cases $(39.96 \%)$ while hysterectomy without removal of adnexa structures were seen in 380 cases (34.99\%). Hysterectomy with unilateral adnexa structures were seen in 272 cases; with left salpingo-oophorectomy constituting 166 cases $(15.29 \%)$ and right salpingooophorectomy constituting 106 cases $(9.76 \%)$. 
The commonest indication for hysterectomy was uterine mass which constituted 722 cases $(66.48 \%)$. Dysfunctional uterine bleeding was the indication in 101 cases $(9.3 \%)$ while ovarian tumours and cervical tumours were indication in 109 cases $(10.03 \%)$ and 31 cases $(2.85 \%)$ respectively. Other indications including peripartum haemorrhage, post- partum haemorrhage and placentae disorders as documented in table 1.

Table 1: Clinical indications for Hysterectomy

\begin{tabular}{lc}
\hline Indication for Removal & Frequency (\%) \\
\hline Dysfunctional Uterine Bleeding & $101(9.3 \%)$ \\
Uterine mass & $722(66.42 \%)$ \\
Perforation & $5(0.46 \%)$ \\
Post-Partum Haemorrhage & $9(0.86 \%)$ \\
Utero Vagina Prolapse & $23(2.11 \%)$ \\
Ovarian Tumours & $109(10.03 \%)$ \\
Adenomyosis/ Endometriosis & $15(1.38 \%)$ \\
Cervical Tumours & $31(2.85 \%)$ \\
Ectopic Gestation \& Other Fallo- & $6(0.56 \%)$ \\
pian Tube pathologies & \\
Placenta disorders & $7(0.64 \%)$ \\
Non specific & $15(1.38 \%)$ \\
Not Stated & $43(39.59 \%)$ \\
\hline
\end{tabular}

\section{Data presented as frequency (percentage)}

Findings from gross morphology of Hysterectomy specimens showed that majority of the cases presented with macroscopically obvious lesions in various tissues of the specimen. Masses were seen in the uterus in 737 cases $(67.87 \%)$, while 283 cases (26.06\%) appeared normal morphologically. Lesions seen in the endometrium, cervix, left and right fallopian tubes and ovaries were as depicted in Table 2.

The histological diagnosis from various structures of the hysterectomy specimens were as depicted in tables 3.1-3.4. Uterine leiomyoma is seen in 861 cases (75.41\%). In many of the cases it co-existed with other lesions; Leiomyoma co-existing with Adenomyosis were seen in 83 cases $(7.64 \%)$. Adenomyosis without leiomyoma and malignant tumours of the endometrium were seen in 33 cases $(3.03 \%)$ and 41 cases $(3.78 \%)$ respectively. The frequencies of other lesions in the endometrium were as listed in table 3.

The histological diagnosis from various structures of the hysterectomy specimens were as depicted in

Abdominal hysterectomy in a tertiary hospital Titiloye et al.,

.

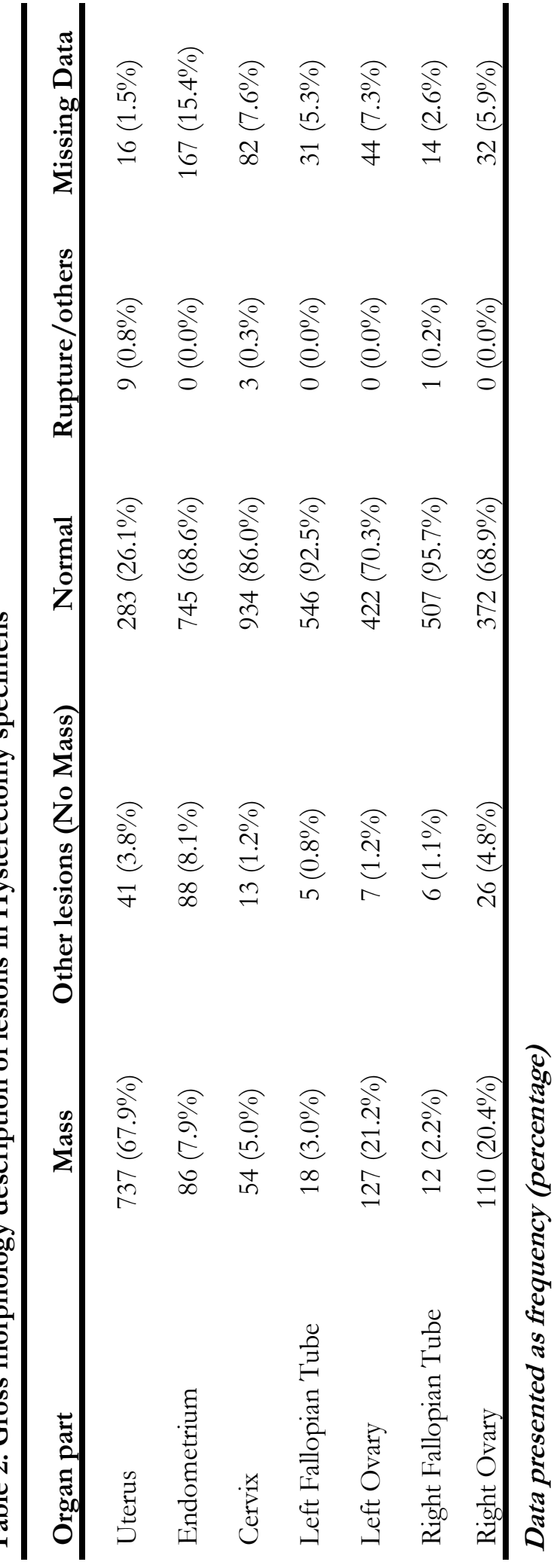




\section{Abdominal hysterectomy in a tertiary hospital}

Titiloye et al.,

tables 3.1-3.4. Uterine leiomyoma is seen in 861 cases $(75.41 \%)$. In many of the cases it co-existed with other lesions; Leiomyoma co-existing with Adenomyosis were seen in 83 cases $(7.64 \%)$. Adenomyosis without leiomyoma and malignant tumours of the endometrium were seen in 33 cases (3.03\%) and 41 cases $(3.78 \%)$ respectively. The frequencies of other lesions in the endometrium were as listed in table 3.

Table 3: Histology and frequency of lesion in the corpus uteri and endometrium

\begin{tabular}{lc}
\hline Variants & Frequency \\
\hline Normal & $125(11.51 \%)$ \\
Leiomyoma & $736(67.77 \%)$ \\
Adenomyosis + Leiomyoma & $83(7.64 \%)$ \\
Adenomyosis & $33(3.04 \%)$ \\
Endometrial Adenocarcinoma & $43(3.96 \%)$ \\
Utero-Vaginal Prolapse & $4(0.37 \%)$ \\
Placenta Accreta & $3(0.28 \%)$ \\
Chronic Endometritis & $12(1.10 \%)$ \\
Uterine Ruptured & $2(0.18 \%)$ \\
Perforated Uterus & $2(0.18 \%)$ \\
Endometrial Hyperplasia & $26(2.39 \%)$ \\
Product of Conception & $11(1.01 \%)$ \\
Endometrial Polyp & $6(0.55 \%)$ \\
Total & $1086(100 \%)$ \\
\hline
\end{tabular}

Data presented as frequency (percentage)

In the cervix squamous cell carcinoma were seen in 12 cases $(1.1 \%)$. The frequencies of other lesions of the cervix were listed in table 4.

Table 4: Histology and frequency of lesion in the cervix

\begin{tabular}{lc}
\hline Variants & Frequency \\
\hline Normal & $600(54.95 \%)$ \\
Cervicitis & $273(25 \%)$ \\
Leiomyoma & $1(0.09 \%)$ \\
Squamous Metaplasia & $43(3.94 \%)$ \\
Squamous cell carcinoma & $12(1.10 \%)$ \\
Cervical Polyp & $5(0.46 \%)$ \\
Metastasis & $3(0.27 \%)$ \\
Adenocarcinoma & $2(0.18 \%)$ \\
UV Prolapse & $4(0.37 \%)$ \\
CIN-1 with HPV & $4(0.37 \%)$ \\
CIN-II & $2(0.18 \%)$ \\
CIN-III & $4(0.37 \%)$ \\
Not removed surgically or not reported & $139(12.73 \%)$ \\
\hline
\end{tabular}

Data presented as frequency (percentage)
One thousand and eight seven (1087) cases $(95.35 \%)$ of left and right fallopian tubes were normal while salpingitis was seen in 38 cases $(3.33 \%)$. The frequency of other fallopian tubes lesions which include product of conception, metastasis and primary lymphoma were as depicted in table 5 .

Table 5: Histology and frequency of lesion in the fallopian tubes

\begin{tabular}{lcc}
\hline Variants & $\begin{array}{c}\text { Left Fallopian } \\
\text { Tube }\end{array}$ & $\begin{array}{c}\text { Right Fallopian } \\
\text { Tube }\end{array}$ \\
\hline Total & $600(100 \%)$ & $540(100 \%)$ \\
No lesion & $568(94.67 \%)$ & $519(96.11 \%)$ \\
Salpingitis & $23(3.83 \%)$ & $15(2.78 \%)$ \\
Fibrosis & $1(0.17 \%)$ & $1(0.19 \%)$ \\
Metastasis & $6(1 \%)$ & $2(0.37 \%)$ \\
Product of & $1(0.17 \%)$ & $2(0.37 \%)$ \\
conception & & \\
\hline
\end{tabular}

Data presented as frequency (percentage)

Seven hundred and twenty-nine (729) cases $(63.95 \%)$ of left and right ovaries had no lesion in them. Corpus luteum and other benign cysts of the ovaries were seen in 313 cases $(27.46 \%)$. Primary tumours of the ovary which is composed of benign

Table 6: Histology and frequency of lesion in the ovaries

\begin{tabular}{lcc}
\hline Variants & Left Ovary & Right Ovary \\
\hline Total & $600(100 \%)$ & $540(100 \%)$ \\
No lesion & $376(62.7 \%)$ & $353(65.4 \%)$ \\
Corpus luteum cyst & $84(14 \%)$ & $60(11.11 \%)$ \\
Cyst (Uncategorized) & $91(15.17 \%)$ & $78(14.44 \%)$ \\
Endometriosis & $2(0.33 \%)$ & $1(0.19 \%)$ \\
Metastatic tumour & $5(0.83 \%)$ & $5(0.93 \%)$ \\
Ovarian abscess & $2(0.33 \%)$ & $0(0 \%)$ \\
Primary tumours & $40(6.67 \%)$ & $43(7.96 \%)$ \\
Primary tumours & & \\
Benign & & \\
Mature teratoma & 7 & 6 \\
Fibroma & 4 & 5 \\
Brenner tumour & 5 & 4 \\
Mucinous cystadenoma & 2 & 0 \\
Malignant & & \\
Granuloma cell tumour & 7 & 5 \\
Serous adenocarcinoma & 14 & 2 \\
Lymphoma & 1 & 1 \\
Malignant mixed tumour & 0 & 5 \\
Mucinous adenocarcinoma & 0 & \\
\hline
\end{tabular}

Data presented as frequency (percentage) 
and malignant tumours were seen in 51 cases $(4.9 \%)$ and 50 cases $(4.80 \%)$ respectively. The commonest benign tumour is mature teratoma with 11 cases $(0.96 \%)$ and serous adenocarcinoma was the commonest malignant tumour with 29 cases $(2.54 \%)$. Metastases to the ovary were seen in 10 cases $(0.88 \%)$. Other tumours were as depicted in table 6 .

As shown in table 7, data from the gross morphology and histology showed strong correlation with clinical indication in 0.98 and 0.99 of the cases respectively.

\section{Abdominal hysterectomy in a tertiary hospital Titiloye et al.,}

in contrast to 30 to 60 years age group in other studies (Orji et al., 2002; Samaila et al., 2009).

Various clinical indications for hysterectomies in the current study include dysfunctional uterine bleeding, uterine mass, uterine perforation and ovarian tumours. Uterine mass as the commonest clinical indication $(66.42 \%)$ in our study was similar to most other studies worldwide. Yadav et al in a series from India found a pre-operative diagnosis of uterine mass in $48.57 \%$ of cases while Samaila et al. (2009) found uterine fibroid to be $61.8 \%$ of cas-

Table 7: Correlations of gross morphology and histology with clinical indication

\begin{tabular}{llccc}
\hline & & Histological Diagnosis & Clinical Indication & Gross Morphology \\
\hline \multirow{2}{*}{$\begin{array}{l}\text { Histological } \\
\text { sis }\end{array}$} & Pearson Correlation & 1 & $0.983^{* *}$ & $0.980^{* *}$ \\
& Sig. (2-tailed) & & 0.000 & 0.000 \\
Clinical Indication & N & 1082 & 1082 & 1082 \\
& Pearson Correlation & $0.983^{* *}$ & 1 & $0.994^{* *}$ \\
& Sig. (2-tailed) & 0.000 & & 0.000 \\
Gross Morphology & Pearson Correlation & 1082 & 1082 & 1082 \\
& Sig. (2-tailed) & $0.980^{* *}$ & $0.994^{* *}$ & 1 \\
& $\mathrm{~N}$ & 0.000 & 0.000 & 1082 \\
\hline
\end{tabular}

** Correlation is significant at the 0.01 level (2-tailed)

\section{DISCUSSION}

Despite the unfavourable cultural disposition to hysterectomy in our environment, hysterectomy specimens still remain one of the major sources of specimens submitted for histological appraisal in most pathology department as seen worldwide (Wu et al., 2007; Ezem and Otubu 1981). This current study showed about 3\% which is comparable to previous studies (Samaila et al., 2009). The fifth decade peak age for patients and the other patterns seen in other age groups in our study have been documented in many previous studies (Suad et al., 2017; Khunte et al., 2017).

Women offered hysterectomy more often have completed their family and have uterus related disorder in which hysterectomy is therapeutic. In our series, hysterectomy was not performed for any woman as a form of family planning. Our study showed patient age spectrum of 15-85 years suggesting that hysterectomies were done for reproductive and nonreproductive age groups based on wide indications es in Zaria. This is in agreement with many other studies conducted on black Africans (Roberts and Okunlola 2005; Onwuhafua et al., 2005; Gupta et al., 2009). The lesions from gross morphologic appearance showed uterine mass as the predominant lesion similar to histological diagnosis. It is of note that adenomyosis was seen more in association with uterine fibroid than occurring alone. Most of our patents were multiparous with large percentage at the reproductive age groups and studies have shown that unlike endometriosis which has been strongly associated with a form of sub-fertility, adenomyosis seen in hysterectomy specimen of patients in the fifth decade lack such association (Campo et al., 2012; De Ziegler et al., 2010; Lee et al., 1984).

Endometrial carcinoma was the histological diagnosis in 43 cases constituting the second largest histological lesions in the uterus. Our study also found other variable diagnosis which may have been indication for the hysterectomy or co-exist with other 


\section{Abdominal hysterectomy in a tertiary hospital}

Titiloye et al.,

lesions in the hysterectomy specimen. However, 125 cases of the uterus were considered normal. Though the uterus may not contain lesions, malignancies seen in the ovary, cervix and rarely the fallopian tubes may warrant hysterectomy. In our series, primary ovarian malignancies were seen in 28 cases and metastases to the ovaries were seen in 5 cases. Cervical malignancies were seen in 17 cases with 15 cases being squamous cell carcinoma, 2 cases of adenocarcinoma and 3 were direct spread and metastasis from the endometrium.

Other non-neoplastic conditions including UV prolapse and complications of obstetrics procedure which include uterine perforation, placenta accreta and uterine rupture were histological diagnoses for hysterectomies in this series. Also this series documented a wide array of lesions which were accidental findings co-existing with the main pathology. Few hysterectomy specimens constituting less than $10 \%$ had no pathology in them. Our data on the cases with pathologies and without pathology were similar to other studies by Adelusola and Ogunniyi (2001) and Samaila et al. (2009).

Our study showed a strong correlation between clinical impression and pathological diagnoses similar to previous studies (Gupta et al., 2010; Khunte et al., 2017; Rather et al., 2013).

\section{CONCLUSION}

Hysterectomies with or without salpingooophorectomy were common histological specimen in our laboratory, often done for women in the fifth decade. The commonest indication and pathological diagnosis was leiomyoma. Our histopathological diagnoses showed strong correlation with clinical indication in most of the cases.

\section{COMPETING INTERESTS}

The authors declare that they have no competing interests.

\section{ACKNOWLEDGEMENTS}

We acknowledge the staff of Department of Pathology, Komfo Anokye Teaching Hospital, Kumasi for their assistance in this study and we appreciate
Messrs William Ayibor and Flynt Ntim; and Miss Henrietta Somuah-Frempong for assisting in data collection.

\section{REFERENCES}

Adelusola K. and Ogunniyi S. (2001) Hysterectomies in Nigerians: histopathological analysis of cases seen in Ile-Ife. The Nigerian postgraduate medical journal 8(1), 37-40.

Campo S, Campo V, Benangiano G (2012). Adenomyosis and infertility; Review article. Obstetrics and Gynaecology International. Article ID 786132, 8 pages

De Ziegler D, Borghese B, Chapron C. Endometriosis and infertility : Pathophysiology and management. The Lancet. 2010; vol 376, no 9742 , pp. $730-738$

Ezem BU, Otubu JA. Hysterectomy in the Hausa/ fulani population in Nigeria. Int J Gynecol Obstet 1981;19:145-9.

Graves, EJ. National Center for Health Statistics, National Hospital discharge survey: annual summary, 1990. Viral Health stat (13). 1992, No.112. DHHS Publication PHS 921773.

Gupta G., Kotasthane D. and Kotasthane V. (2010) Hysterectomy: a clinico-pathological correlation of 500 cases. The Internet Journal of Gynaecology and Obstetrics 14(1), 1-5.

Khunte V., Kulkarni V., Gahine R. and Indoria C. (2017) Spectrum of Lesions in Hysterectomy Specimens and their Preoperative Correlation. J Cont Med A Dent. 5(3), 29-33.

Kwame-Aryee RA, Kwakye AK, Seffah JD. Peripartum Hysterectomy at Korle $-\mathrm{Bu}$ Teaching Hospital: A review of 182 consecutive cases. Ghana Med J. 2007 Sep; 41 (3); 133-138

Lee NC, Dicker RC, Rubin GL, Ory HW. Confirmation of the pre-operative diagnosis of hysterectomy. American Journal of Obstetrics and Gynaecology. 1984; Vol 150, no 3 , pp. 283-287

Onwuhafua PI, Oguntayo A, Adesiyun G, Obineche I, Akuse JT. Audit of hysterectomies in a group of private hospitals in $\mathrm{Ka}$ - 


\section{Abdominal hysterectomy in a tertiary hospital}

Titiloye et al.,

duna City, Nothern Nigeria. Trop J Obstet 2005; 22:16-20

Orji EO, Ndububa VI, Ajenifuja KO. Elective Hysterectomy in Obafemi Awolowo University Teaching Hospitals Complex, Ile-Ife. Sahel Med J 2002;5:125-8.

Rather GR, Gupta Y, Bardhwaj S. Pattern of lesions in Hysterectomy specimens: a prospective study. JK Science. 2013; vol 15, no 2.

Roberts OA, Okunlola MA. Abdominal hysterectomy for benign gynaecological conditions at Ibadan, Nigeria. Trop J Obstet Gynaecol 2005; 22:125

Samaila MO , Adesiyun AG, Agunbiade OA , Mohammed-Duro A. Clinico-Pathological assessment of hysterectomies in Zaria. Euro- pean Journal of General Medicine, Vol. 6, No. 3, July-September, 2009, pp. 150-153

Suad MO. Zaid, Mazen Abood Ben Thabet. Histopathological findings in hysterectomy specimens: A retrospective study. Middle East Journal of Internal Medicine. 2017; Vol 10, issue 3

Takyi C. Indications and outcome of Hysterectomy at Korle Bu: Afive year review. Thesis (MPH) - University of Ghana. 2013; Http://197.255.68 $203 /$ handle/123456789/5249

Wu J.M., Wechter M.E., Geller E.J., Nguyen T.V. and Visco A.G. (2007) Hysterectomy rates in the United States, 2003. Obstetrics \& Gynecology 110(5), 1091-1095.
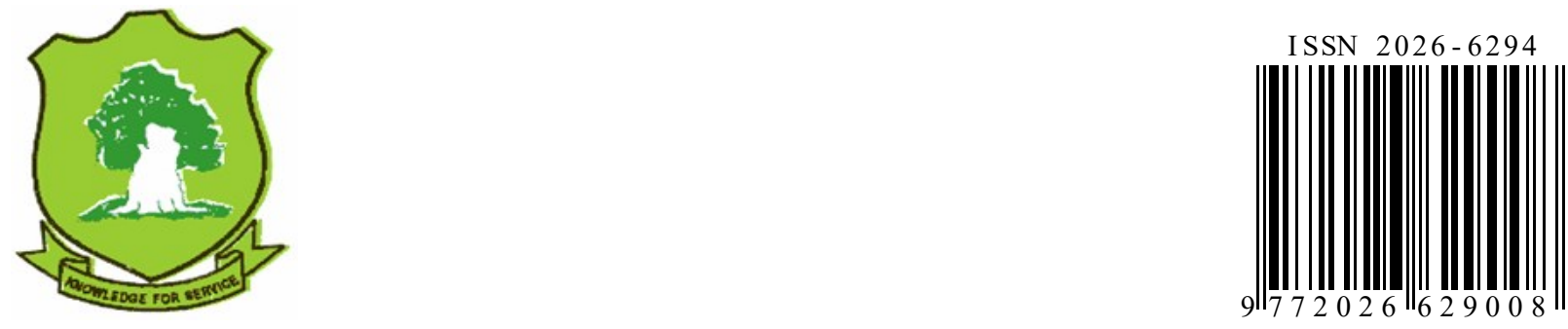